\title{
Phosphatase of Regenerating Liver-3 Induces Angiogenesis by Increasing Extracellular Signal-Regulated Kinase Phosphorylation in Endometrial Adenocarcinoma
}

\author{
Jian Ming a, b Yanduo Jiang ${ }^{b}$ Guocheng Jiang $^{b}$ Huachuan Zheng ${ }^{a}$ \\ ${ }^{a}$ Department of Biochemistry and Molecular Biology, College of Basic Medicine, China Medical University, and \\ bNo. 202 Hospital of People's Liberation Army of China, Shenyang, PR China
}

\section{Key Words}

Endometrial adenocarcinoma. Phosphatase of regenerating liver-3 - Extracellular signal-regulated kinase . Vascular endothelial growth factor · Angiogenesis

\begin{abstract}
Objective: The aim of this study was to investigate the mechanism by which phosphatase of regenerating liver-3 (PRL-3) induces angiogenesis in endometrial adenocarcinoma tissues and cells. Methods: We investigated the expression of PRL-3 and vascular endothelial growth factor (VEGF) in samples from 124 patients with endometrial adenocarcinoma using immunohistochemical staining. The relationship between PRL-3 expression and microvessel density (MVD), clinicopathological factors and surgical treatment outcome was also studied. Following this, we studied the effect on cell lines of blocking or upregulating PRL-3. Results: PRL-3 expression in endometrial adenocarcinoma was high, and this overexpression is correlated with advanced clinical stage $(p=0.008)$, lymph node metastasis $(p=0.016)$ and poor postoperative survival. PRL-3 overexpression was associated with VEGF $(p=0.001)$ expression and MVD $(p=0.005)$. Upregulating PRL-3 expression promoted VEGF and phosphorylated extracellular signal-regulated kinase ( $p E R K$ ) expression. Blocking PRL-3 expression inhibited VEGF and pERK ex-
\end{abstract}

pression. Following inhibition of pERK, VEGF expression was downregulated. Conclusions: PRL-3 induces microvascular vessel formation by facilitating VEGF expression in endometrial adenocarcinoma tissues. PRL-3 upregulates pERK expression and activity, facilitating VEGF expression and accelerating angiogenesis.

Copyright $\odot 2013$ S. Karger AG, Basel

\section{Introduction}

Phosphatase of regenerating liver-3 (PRL-3) is a tyrosine phosphatase. PRL-3 mRNA is expressed primarily in heart and skeletal muscle, with lower expression levels in the spleen, pancreas and testis in normal adult human tissues $[1,2]$. In the last few years, evidence has shown that PRL-3 expression is correlated with many human tumors. Using global gene expression profiling of colorectal cancer samples, PRL-3 was the only gene expressed at high levels in metastatic colorectal cancer cells but at lower levels in primary tumors and normal epithelium [3]. Subsequently, many data showed that PRL-3 was highly expressed in many tumors, including breast cancer, ovarian cancer, intestinal cancer, gliomas, gastric cancer, oral squamous cell cancer, non-small cell lung cancer, intrahepatic cholangiocarcinoma and hepatocellular carcinoma

\section{KARGER}

E-Mail karger@karger.com

www.karger.com/pat
(C) 2013 S. Karger AG, Base

1015-2008/14/0811-0001\$39.50/0 
[4-12]. PRL-3 expression has also been reported in Hodgkin's lymphoma, ovarian cancer, melanomas, breast cancer, liver cancer and gastric cancer cell lines, where its presence seems to play an important role in the acquisition of metastatic potential by tumor cells $[7,13,14]$. In addition, PRL-3 overexpression is associated with the metastatic potential and poor prognosis of many tumors, such as colorectal cancer, ovarian cancer, gastric cancer, cervical cancer, breast cancer and lung cancer [15]. However, the level of PRL-3 expression in endometrial cancer is not yet known, and the mechanism by which PRL-3 induces microvascular formation has not been elucidated.

Endometrial cancer is the sixth most commonly diagnosed cancer in females worldwide, accounting for 5\% $(287,100)$ of the total new cancer cases in 2008 [16]. The incidence of this disease has increased rapidly because of risk factors such as improper physical activity, dietary intake, obesity, unopposed estrogen replacement in the menopause, diabetes, hypertension, nulliparity and later menopausal age, among others. Jung et al. [17] found that extracellular signal-regulated kinase (ERK) is phosphorylated to pERK and transferred into the cell nucleus, and further that pERK promotes VEGF gene transcription and modulates vascular formation. In order to elucidate the role of PRL-3 in endometrial cancer progression, we investigated PRL-3 expression in tumor and adjacent normal tissues from 124 endometrial adenocarcinoma patients. We further studied the relationship between PRL-3 expression and clinical and pathological prognostic factors. Other factors such as vascular endothelial growth factor (VEGF) and microvessel density (MVD) were also investigated. At the same time, we selected endometrial cancer cell lines with expression of PRL-3 to investigate the mechanisms underlying the effects of PRL-3 on angiogenesis.

\section{Materials and Methods}

\section{Sample Preparation}

Endometrial adenocarcinoma tissues from a total of 124 cases were obtained from 1 January 2000 to 31 December 2007 at the First Affiliated Hospital of China Medical University. None of the 124 cases had received radiation therapy or chemotherapy before surgery. The 124 samples (well differentiated: 86; moderately differentiated: 22; poorly differentiated: 16) were fixed in formalin and embedded in paraffin. Tumor size and metastatic lymph node number and locations were obtained from the pathology reports. All tumors were staged according to the International Federation of Gynecology and Obstetrics (2009) criteria. All patients underwent abdominal hysterectomy and bilateral oophorectomy. Pelvic and paraaortic lymphadenectomy was performed at stage IB (32 cases), stage II ( 14 cases) and stage III ( 22 cases). Of these cases, 20 showed lymph node metastasis. The survival time was calculated from the day of operation to death via the evaluation of recurrence and metastasis or until the last follow-up date (December 2011). The follow-up of the surviving patients averaged 35.83 months and ranged from 5 to 124 months. The study was approved by the First Affiliated Hospital Ethical Committee of China Medical University.

\section{Immunohistochemical Staining}

Four-micron-thick sections were prepared from the paraffinembedded tissues. Immunostaining was performed by the streptavidin-peroxidase method (Ultrasensitive ${ }^{\mathrm{TM}}$, MaiXin, Fuzhou, China). The primary antibodies were anti-PRL-3 (1:100; Santa Cruz, Calif., USA), anti-VEGF (1:100; Santa Cruz) and anti-CD34 monoclonal (ready to use; MaiXin) antibodies. The peroxidase reaction was developed with 3,3'-diaminobenzidine tetrahydrochloride (MaiXin). For negative control, the primary antibodies were replaced by PBS.

All the samples were evaluated by 2 independent pathologists (Y.J. and J.M.). A section was considered negative or positive according to the absence or presence of positive staining, respectively. The staining was scored as follows: PRL-3-positive tumor cells $\leq 50 \%$, low expression, and $>50 \%$, high expression; and VEGF-positive tumor cells $\geq 10 \%$, positive expression, and $<10 \%$, negative expression. Blood vessel staining was used as evaluation criteria as follows: brown-yellow-stained endothelial cells with band- or fissure-like isolated or clustered structures or with a tubular lumen were counted as a single blood vessel. Within each section, we selected 3 tumor areas with the highest density of distinctly highlighted microvessels ('hot spot') when observed under low-power fields. Next, the average number of CD34-labeled tubular lumens was counted under high-power fields [18]. MVD was calculated as the mean CD34-labeled tubular lumen number. If the difference between the numbers counted by the 2 pathologists was more than $10 \%$, the lumens were recounted and a consensus between the observers was reached [19].

\section{Cell Culture}

The cell lines used in this study were HEC-1-B and AN3 CA (endometrial adenocarcinoma). They were cultured in minimum essential medium (MEM; Gibco, USA) containing 10\% FBS (Gibco), $100 \mathrm{U} / \mathrm{ml}$ penicillin and $100 \mathrm{U} / \mathrm{ml}$ streptomycin at $37^{\circ} \mathrm{C}$ with $5 \% \mathrm{CO}_{2}$ until $75 \%$ confluent. Cells were incubated with MEM [including, respectively, active human recombinant PRL-3 SRP0210 (100 ng/ml; Sigma) and ERK1/2 inhibitor PD98059 (10 $\mu \mathrm{mol} / \mathrm{ml}$; Cell Signaling, USA)].

\section{PRL-3 Small Interfering RNA Transfection}

HEC-1-B and AN3 CA cells $\left(5 \times 10^{4}\right.$ per well) were plated in a 24 -well plate in medium without antibiotics $24 \mathrm{~h}$ before transfection. All transfections were carried out in triplicate. The protocol for small interfering RNA (siRNA) transfection in a 24-well format (Invitrogen) using Lipofectamine ${ }^{\mathrm{TM}} 2000$ reagent (Invitrogen) was followed for all transfections. The general procedure was as follows: (1) siRNA ( $20 \mathrm{pmol} ; 1 \mu \mathrm{l}$ of a $20-\mu \mathrm{mol} / 1$ solution) was added to $50 \mu \mathrm{l}$ of MEM reduced-serum medium; (b) Lipofectamine 2000 $(1 \mu \mathrm{l})$ was added to $50 \mu \mathrm{l}$ of MEM reduced-serum medium and incubated for 5 min at room temperature; (3) the siRNA and Lipofectamine were mixed and incubated at room temperature for 20 min, and (4) the 100- $\mu$ l mixture was added to the cells. The follow- 


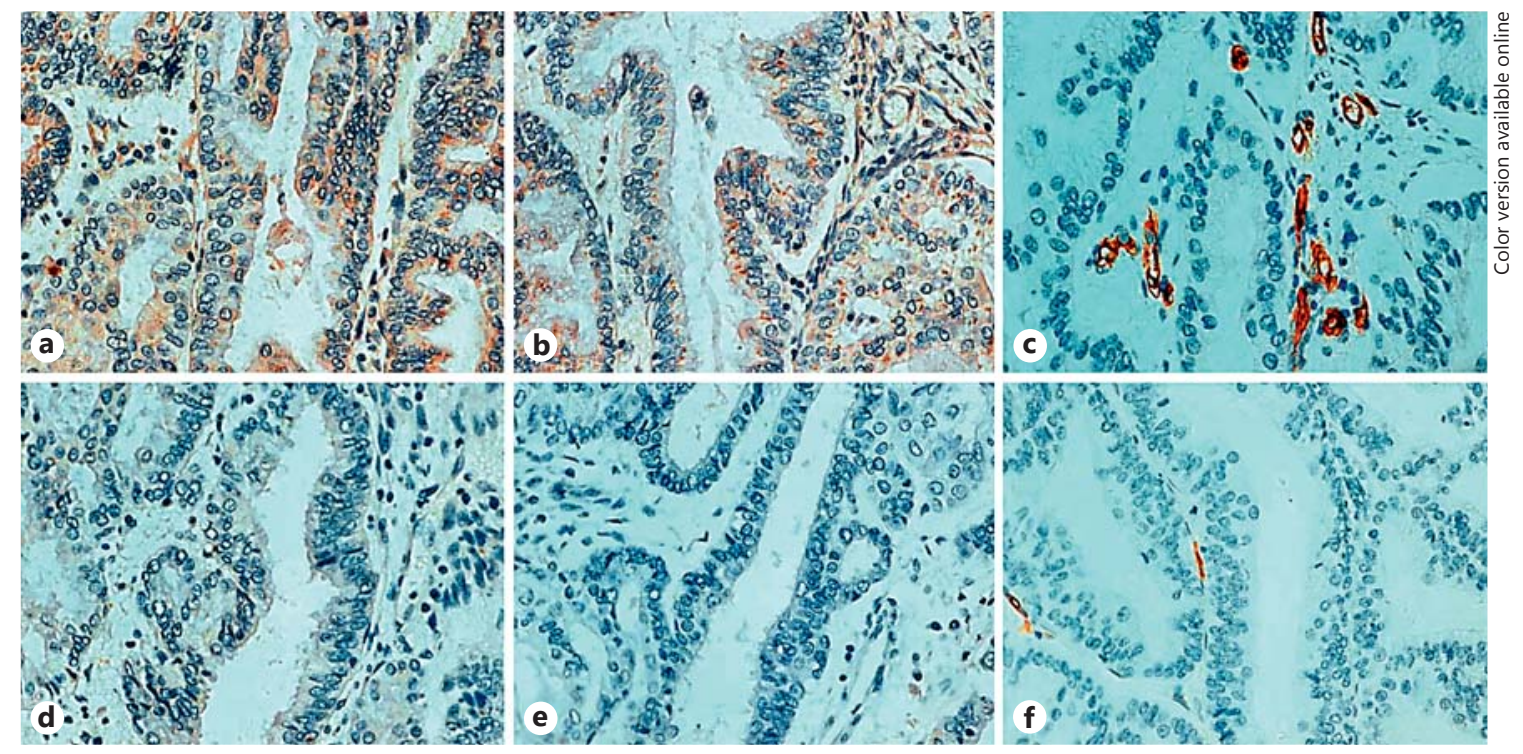

Fig. 1. Relationship between the expression of PRL-3 and VEGF in endometrial adenocarcinoma and MVD (immunohistochemical streptavidin-peroxidase method). Brown-yellow particles of PRL-3 and VEGF were observed in cancer cells. When the expression level of these molecules was high (a, b, respectively), the corresponding CD34-labeled MVD was also high (c), while when the expression level of these molecules was low (d, e, respectively), the corresponding MVD was significantly low (f). $\times 400$.

ing siRNAs were used: siRNA Negative-1 (Ambion) and siRNA against PRL-3 (Xeragon/Qiagen; target sequence: TGAGAGCGGGATGAAGTACGA). siRNAs were provided by Beverly A. Teicher of Genzyme Corp.

\section{Western Blotting}

The cells were extracted with lysis buffer (150 mM NaCl, 1\% NP-40, $0.1 \%$ SDS, $2 \mu \mathrm{g} / \mathrm{ml}$ aprotinin, $1 \mathrm{mM}$ PMSF) for 1 or $24 \mathrm{~h}$ at $4^{\circ} \mathrm{C}$. The supernatants were centrifuged at $12,000 \mathrm{~g}$ for $30 \mathrm{~min}$ at $4^{\circ} \mathrm{C}$. The supernatant containing total protein was harvested. Aliquots containing $60 \mu \mathrm{g}$ of proteins were separated on a $12 \%$ SDSpolyacrylamide gel and transferred to polyvinylidene difluoride membranes. The membranes were blocked with $5 \%$ skimmed milk and respectively incubated with anti-VEGF, anti-ERK1/2, antipERK and anti- $\beta$-actin (1:200; Santa Cruz) at $4^{\circ} \mathrm{C}$ overnight, followed by each corresponding secondary antibody (1:2,500; Chemicon, USA) at room temperature for $2 \mathrm{~h}$. Next, 3,3'-diaminobenzidine tetrahydrochloride visualization and then densitometric analysis of the bands was performed.

Reverse Transcription-Polymerase Chain Reaction

Total RNA was isolated from cells in the logarithmic growth phase using TRIZOL (Invitrogen). The PCR primers were as follows: PRL-3 forward, 5'-GGGACTTCTCAGGTCGTGTC-3', PRL-3 reverse, $5^{\prime}$-AGCCCCGTACTTCTTCAGGT-3' (length 245 bp); VEGF forward, 5'-TCATCACGAAGTGGTGAAGTT-3', VEGF reverse, $5^{\prime}$-ATGCTTTCTCCGCTCTGA-3' (length 349 bp), and $\beta$-actin forward, $5^{\prime}$-AAATCGTGCGTGACATTAA- $3^{\prime}, \beta$-actin reverse, $5^{\prime}$-CTCGTCATACTCCTGCTTG-3' (length 513 bp).
Statistical Analysis

The statistical package SPSS 13.0 (SPSS Inc., Chicago, Ill., USA) was used for all analyses. The $\chi^{2}$ test, Kaplan-Meier curves, t test, log-rank test and Cox regression multivariate analysis were used to analyze data. Values of $\mathrm{p}<0.05$ were considered statistically significant.

\section{Results}

\section{Correlation of the Expression of $P R L-3$ and}

$V E G F$ in Endometrial Adenocarcinoma with

Clinicopathological Factors

PRL-3 was expressed in all 124 cases but with variable expression levels. The proportion of positive cells ranged from 10 to $90 \%$. The frequency of high expression of PRL3 was $67.74 \%(84 / 124)$. No PRL-3 expression was observed in the endometrial cells in cancer-adjacent tissues. PRL-3 expression occurred mainly in the cytoplasm (fig. 1).

The expression rate of VEGF in the 124 cases was $61.29 \%$ (76/124); it was expressed in the cytoplasm (fig. 1). PRL-3 overexpression was positively correlated with the positive expression of VEGF $\left(\chi^{2}=0.376, p=0.001\right)$.

The relationship between high PRL-3 expression and the clinicopathological factors of endometrial adenocarcinoma is shown in table 1 . The PRL-3 expression level 


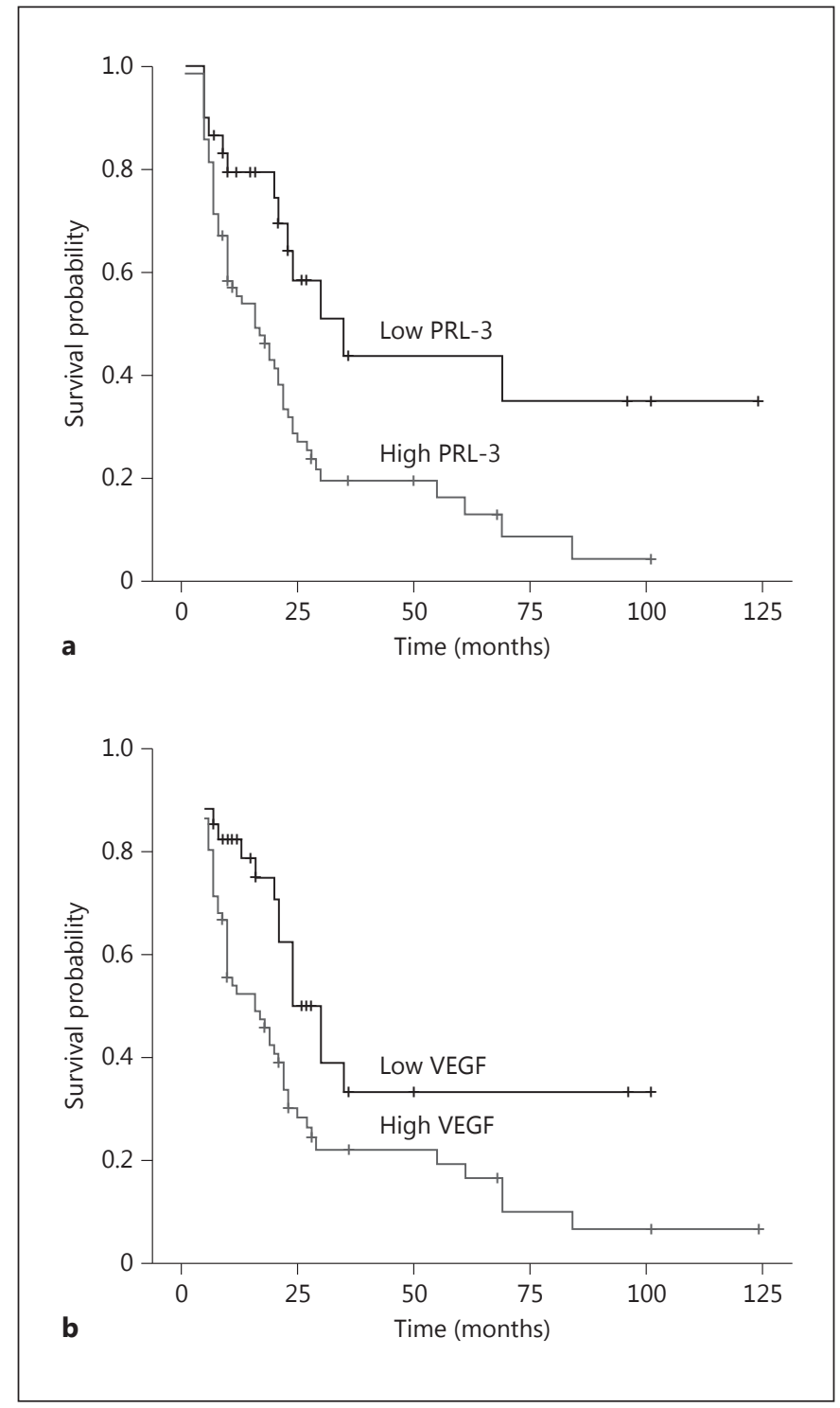

Fig. 2. Survival of endometrial adenocarcinoma patients correlated with the expression of PRL-3 and VEGF. Shown are Kaplan-Meier survival plots for patients with endometrial adenocarcinoma, grouped according to PRL-3 (a) and VEGF (b) protein expression. Correlation between overall survival of patients and PRL-3 expression was found to be statistically significant $(p=0.002)$, as was that between survival rate and VEGF expression $(\mathrm{p}=0.01)$. All patients alive at their last follow-up are indicated by vertical lines on the plot.

was closely correlated with the stage of endometrial adenocarcinoma $\left(\chi^{2}=0.351, \mathrm{p}=0.008\right)$ and lymph node metastasis $\left(\chi^{2}=0.238, \mathrm{p}=0.016\right)$ but was not correlated with age or degree of differentiation of the cancer.

Patients with low expression of PRL-3 had a statistically significantly longer survival than those with high ex-
Table 1. Relationship between PRL-3 expression in endometrial adenocarcinoma and clinical pathological factors

\begin{tabular}{lclll}
\hline & $\mathrm{n}$ & $\begin{array}{l}\text { High PRL-3 } \\
\text { expression, } \mathrm{n}\end{array}$ & $\begin{array}{l}\mathrm{p} \\
\text { value }\end{array}$ & $\begin{array}{l}\chi^{2} \\
\text { value }\end{array}$ \\
\hline Age & & & & \\
$\quad \leq 60$ years & 74 & $51(68.92 \%)$ & & \\
$\quad>60$ years & 50 & $33(66 \%)$ & 0.469 & \\
$\begin{array}{l}\text { Tumor differentiation } \\
\quad \text { Good }\end{array}$ & 86 & $57(66.28 \%)$ & & \\
$\quad$ Moderate and poor & 38 & $27(71.05 \%)$ & 0.342 & \\
$\begin{array}{l}\text { Stage } \\
\text { I }\end{array}$ & 88 & $53(60.23 \%)$ & & \\
$\quad$ II & 14 & $11(78.57 \%)$ & & \\
$\quad$ III & 22 & $20(90.91 \%)$ & 0.008 & 0.351 \\
Lymph node metastasis & & & & \\
$\quad$ Positive & 20 & $18(90 \%)$ & & \\
$\quad$ Negative & 104 & $66(63.46 \%)$ & 0.016 & 0.238 \\
VEGF expression & & & & \\
$\quad \begin{array}{l}\text { Positive } \\
\text { Negative }\end{array}$ & 76 & $61(80.26 \%)$ & & \\
\hline
\end{tabular}

pression of PRL-3 (median survival $16 \pm 3.417$ months, 95\% confidence interval 9.303-22.697 months; $\mathrm{p}=0.002$; fig. 2a). In addition, patients with negative expression of VEGF survived longer than those with positive expression of VEGF (median survival $16 \pm 4.264$ months, $95 \%$ confidence interval 7.672-24.358 months; $\mathrm{p}=0.01$; fig. 2b). In the Cox regression multivariate analysis, PRL3 was one of the strongest predictors of survival. At the same time, lymph node metastasis and tumor stage were also predictors of survival (table 2).

\section{Correlation of the Expression of PRL-3 and VEGF with MVD}

The average MVD in the 124 tumor samples was 36.56 \pm 10.29 . MVD was higher in the patients with positive VEGF expression than in those without VEGF expression $(45.27 \pm 14.21$ vs. $30.51 \pm 12.34 ; \mathrm{p}=0.002)$. Higher MVD $(44.24 \pm 13.45)$ was found in patients with a high level of PRL-3 expression, while lower MVD $(28.12 \pm 10.84)$ was observed in patients with a low level of PRL-3 expression ( $\mathrm{p}=0.005$; fig. 1$)$.

These results provide a possible explanation why patients with high PRL-3 expression were more likely to have a poor prognosis, possibly resulting from PRL3-mediated angiogenesis via upregulation of VEGF in human endometrial adenocarcinoma. Then, we studied the mechanism of PRL-3-mediated angiogenesis in HEC1-B and AN3 CA cells. 
Table 2. Multivariate Cox regression model

\begin{tabular}{lrlll}
\hline & Wald & $\operatorname{Exp}(\mathrm{B})$ & $\begin{array}{l}95.0 \% \mathrm{CI} \\
\text { for } \operatorname{Exp}(\mathrm{B})\end{array}$ & $\mathrm{p}$ \\
\hline $\begin{array}{l}\text { Age } \\
\text { Tumor differentiation }\end{array}$ & 2.018 & 0.711 & $0.429-1.218$ & 0.157 \\
$\quad$ Good & 1.159 & & & \\
$\quad$ Moderate & 1.308 & 0.588 & $0.309-1.394$ & 0.505 \\
$\quad$ Poor & 0.000 & 1.007 & $0.618-1.801$ & 1.003 \\
Stage & & & & \\
$\quad$ I & 23.167 & & & $0.000^{*}$ \\
$\quad$ II & 20.468 & 0.011 & $0.011-0.092$ & $0.000^{*}$ \\
$\quad$ III & 4.231 & 0.294 & $0.091-0.910$ & $0.024^{*}$ \\
Lymph node metastasis & 6.311 & 8.123 & $1.566-30.157$ & $0.007^{*}$ \\
PRL-3 expression & 8.654 & 0.684 & $0.314-1.298$ & $0.004^{*}$ \\
VEGF expression & 2.059 & 0.782 & $0.401-1.204$ & 0.178 \\
MVD & 0.249 & 0.849 & $0.957-1.219$ & 0.594 \\
\hline
\end{tabular}

${ }^{*} \mathrm{p}<0.05 . \operatorname{Exp}(\mathrm{B})=$ Relative Risk; $\mathrm{CI}=$ confidence interval.

Identification of the Efficiency of PRL-3 siRNA

HEC-1-B and AN3 CA cells were lysed 24, 48, 72 and $96 \mathrm{~h}$ after transfection, and mRNA extracts were analyzed by RT-PCR. PRL-3 mRNA levels were significantly decreased in HEC-1-B cells ( $p<0.01$; fig. $3 \mathrm{a})$ and AN3 CA cells ( $p<0.01$; fig. $3 b$ ) exposed to PRL-3 siRNA $48 \mathrm{~h}$ after transfection. Considering the remarkable silencing effect of the PRL-3 siRNA, we used it for the following experiments.

\section{PRL-3 Expression and the Impact of ERK1/2, pERK} and VEGF in Cells

Western blotting results showed that the levels of VEGF and pERK proteins were decreased after blocking PRL-3 in HEC-1-B cells (fig. 4a) and AN3 CA cells (fig. 4b). However, blocking PRL-3 expression did not affect the expression of ERK1/2 proteins in HEC-1-B cells (fig. 4a) and AN3 CA cells (fig. 4b). RT-PCR results showed that the expression of VEGF mRNA was downregulated after blocking PRL-3 expression with siRNA in HEC-1-B cells (fig. 4c) and AN3 CA cells (fig. 4d).

Western blotting results also showed that the levels of VEGF and pERK proteins were increased after incubation with active human recombinant PRL-3 (SRP0210) in HEC-1-B cells (fig. 4a) and AN3 CA cells (fig. 4b). However, promoting PRL-3 expression did not affect the expression of ERK1/2 proteins in HEC-1-B cells (fig. 4a) and AN3 CA cells (fig. 4b). RT-PCR results showed that the expression of VEGF mRNA was upregulated after in-

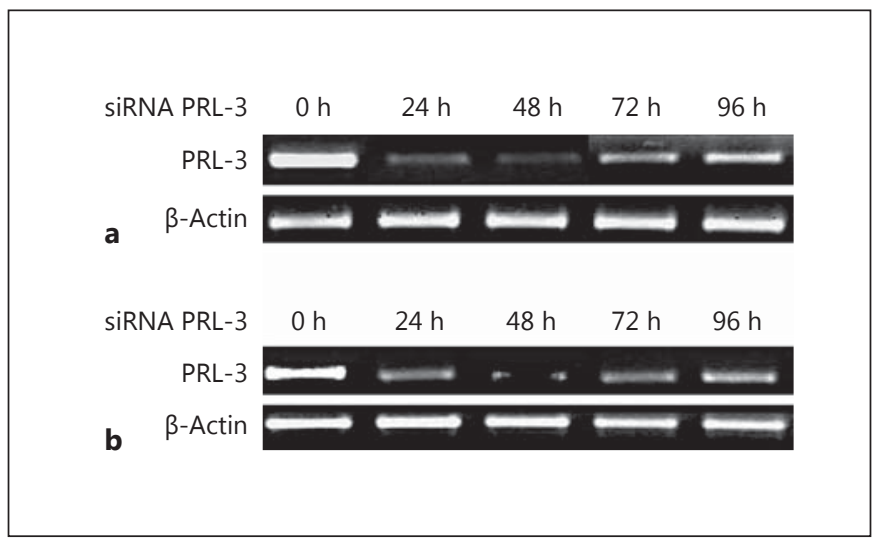

Fig. 3. PRL-3 mRNA levels in HEC-1-B cells (a) and AN3 CA cells (b) were examined by RT-PCR at 0, 24, 48, 72 and $96 \mathrm{~h}$ after transfection with PRL-3 siRNA. PRL-3 mRNA levels in the two cell lines were significantly decreased in cells exposed to PRL-3 siRNA $48 \mathrm{~h}$ after transfection $(\mathrm{p}<0.01)$.

cubation with human recombinant PRL-3 in HEC-1-B cells (fig. 4a) and AN3 CA cells (fig. 4b).

\section{Suppressing the Activity of ERK and the Effect on}

VEGF in Cells

RT-PCR results showed that the expression of VEGF mRNA was reduced after inhibiting the activity of ERK with PD98059 in HEC-1-B cells (fig. 4e) and AN3 CA cells (fig. 4f). Western blotting results showed that the levels of VEGF protein were decreased after inhibiting the activity of ERK in HEC-1-B cells (fig. 4g) and AN3 CA cells (fig. 4h).

\section{Discussion}

In this study, we detected the expression level of PRL3 in cancer tissues and cancer-adjacent normal tissues in 124 cases with endometrial adenocarcinoma using an immunohistochemical method. We found that PRL-3 was expressed in all 124 cases, with a high expression rate of 67.74\%; moreover, high-level PRL-3 expression was obviously associated with advanced clinical stage and the presence of metastases in lymph nodes. The survival rate in patients with low PRL-3 expression was significantly higher than in patients with high expression. PRL-3 expression, lymph node metastasis and tumor stage were the strongest predictors of survival. 
Fig. 4. Blocking PRL-3 expression with siRNA downregulated the levels of VEGF and pERK proteins in HEC-1-B cells (a) and AN3 CA cells (b). However, blocking PRL-3 expression did not affect the expression of ERK1/2 proteins in HEC-1-B cells (a) and AN3 CA cells (b). Upregulating the expression of PRL-3 with human recombinant PRL-3 (SRP0210) increased the levels of VEGF and pERK proteins in HEC-1-B cells (a) and AN3 CA cells (b). However, the expression of ERK1/2 proteins was not affected in HEC-1-B cells (a) and AN3 CA cells (b). Blocking PRL-3 expression with siRNA decreased the expression of VEGF mRNA in HEC-1-B cells (c) and AN3 CA cells (d). Inhibiting the phosphorylation of ERK with PD98059 downregulated the expression of VEGF mRNA and proteins in HEC-1-B cells $(\mathbf{e}, \mathbf{g})$ and AN3 CA cells (f, h).

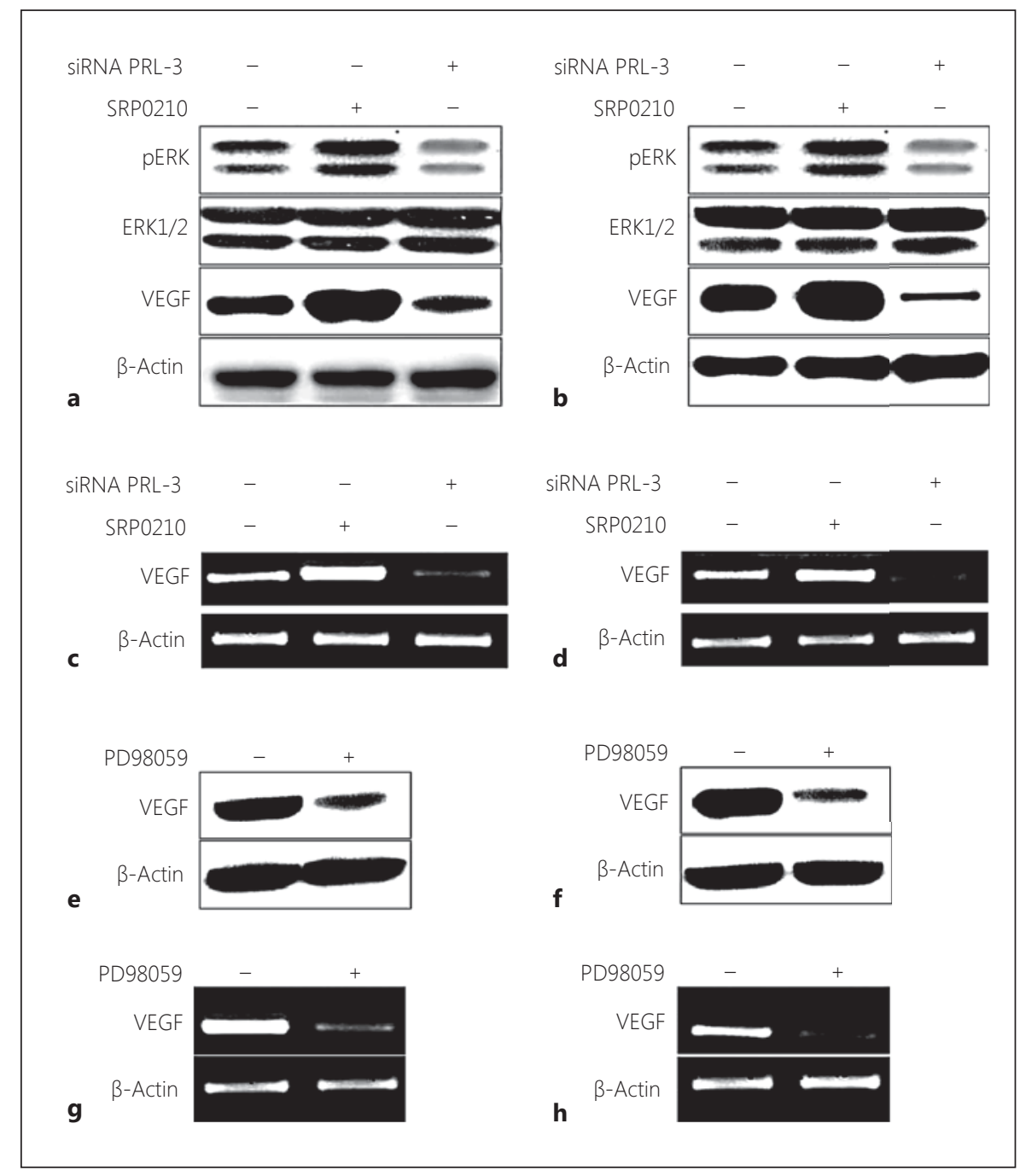

VEGF can induce microvessel formation and promote the proliferation and migration of vascular endothelial cells [20]. VEGF is an important factor of tumor angiogenesis. We also investigated the expression of VEGF and MVD using immunohistochemical methods in this study. The expression of VEGF was significantly correlated with MVD. This is in agreement with the findings of Astekar et al. [21]. Our results showed that PRL-3 overexpression was positively associated with the expression of VEGF. In addition, MVD in the group with high PRL-3 expression was significantly higher than that in the group with low PRL-3 expression. Moreover, in the Cox regression multivariate analysis, PRL-3 was one of the strongest independent predictors of survival; lymph node metastasis and tumor stage were also among the strongest predictors of survival.
These results suggest that PRL-3 overexpression is associated with the degree of malignancy and metastatic potential of endometrial adenocarcinoma cells. Therefore, we suspected that PRL-3 might induce microvascular vessel formation by facilitating VEGF expression in endometrial adenocarcinoma.

We found that high-level PRL-3 expression was significantly associated with VEGF expression and that the expression of both PRL-3 and VEGF was significantly correlated with MVD in endometrial adenocarcinoma tissues. We found that both VEGF and pERK expression was downregulated in endometrial adenocarcinoma cells when PRL-3 expression was blocked with PRL-3 siRNA in those cells. It is well known that ERK is phosphorylated to pERK and transferred into the cell nucleus, and further that pERK promotes VEGF gene transcription 
and modulates vascular formation [17]. We inhibited the phosphorylation of ERK1/2 with the ERK inhibitor PD98059 and found that the expression of VEGF decreased significantly in endometrial adenocarcinoma cells. We upregulated expression of PRL-3 with active human recombinant PRL-3 (SRP0210) and found that both VEGF and pERK expression were upregulated. Our results suggest that PRL-3 could promote VEGF expression by increasing ERK phosphorylation.

\section{Conclusion}

To sum up, we found that PRL-3 could promote VEGF expression by increasing ERK phosphorylation to induce vascular formation in endometrial adenocarcinoma.
PRL-3 expression was positively associated with the expression of VEGF. In addition, PRL-3 was one of the strongest independent predictors of survival.

\section{Acknowledgments}

This work was supported by grants from the Liaoning Province Doctor Startup Fund (No. 20111122). We thank Dr. Cecile Rouleau and Dr. Beverly Teicher from Genzyme Corp. for their kindness in giving us the specific siRNA of PRL-3.

\section{References}

1 Matter WF, Estridge T, Zhang C, Belagaje R, Stancato L, Dixon J, Johnson B, Bloem L, Pickard T, Donaghue M, Acton S, Jeyaseelan R, Kadambi V, Vlahos CJ: Role of PRL-3, a human muscle-specific tyrosine phosphatase, in angiotensin-II signaling. Biochem Biophys Res Commun 2001;283:1061-1068.

-2 Zeng Q, Hong W, Tan YH: Mouse PRL-2 and PRL-3, two potentially prenylated protein tyrosine phosphatases homologous to PRL-1. Biochem Biophys Res Commun 1998;244: 421-427.

-3 Saha S, Bardelli A, Buckhaults P, Velculescu VE, Rago C, St Croix B, Romans KE, Choti MA, Lengauer C, Kinzler KW, Vogelstein B: A phosphatase associated with metastasis of colorectal cancer. Science 2001;294:13431346.

4 Kong L, Li Q, Wang L, Liu Z, Sun T: The value and correlation between PRL-3 expression and matrix metalloproteinase activity and expression in human gliomas. Neuropathology 2007;27:516-521.

5 Miskad UA, Semba S, Kato H, Yokozaki H: Expression of PRL-3 phosphatase in human gastric carcinomas: close correlation with invasion and metastasis. Pathobiology 2004;71: 176-184.

6 Wang Y, Li ZF, He J, Li YL, Zhu GB, Zhang LH, Li YL: Expression of the human phosphatases of regenerating liver (PRLs) in colonic adenocarcinoma and its correlation with lymph node metastasis. Int J Colorectal Dis 2007;22:1179-1184.
7 Radke I, Götte M, Kersting C, Mattsson B, Kiesel L, Wülfing P: Expression and prognostic impact of the protein tyrosine phosphatases PRL-1, PRL-2, and PRL-3 in breast cancer. Br J Cancer 2006;95:347-354.

-8 Polato F, Codegoni A, Fruscio R, Perego P, Mangioni C, Saha S, Bardelli A, Broggini M: PRL-3 phosphatase is implicated in ovarian cancer growth. Clin Cancer Res 2005;11: 6835-6839.

9 Hassan NM, Hamada J, Kameyama T, Tada M, Nakagawa K, Yoshida S, Kashiwazaki H, Yamazaki Y, Suzuki Y, Sasaki A, Nagatsuka $\mathrm{H}$, Inoue $\mathrm{N}$, Moriuchi $\mathrm{T}$ : Increased expression of the PRL-3 gene in human oral squamous cell carcinoma and dysplasia tissues. Asian Pac J Cancer Prev 2011;12:947-951.

10 Xu Y, Zhu M, Zhang S, Liu H, Li T, Qin C: Expression and prognostic value of PRL-3 in human intrahepatic cholangiocarcinoma. Pathol Oncol Res 2010;16:169-175.

11 Ming J, Liu N, Gu Y, Qiu X, Wang EH: PRL-3 facilitates angiogenesis and metastasis by increasing ERK phosphorylation and up-regulating the levels and activities of Rho-A/C in lung cancer. Pathology 2009;41:118-126.

12 Zhao WB, Li Y, Liu X, Zhang LY, Wang X: Evaluation of PRL-3 expression, and its correlation with angiogenesis and invasion in hepatocellular carcinoma. Int J Mol Med 2008; 22:187-192.

13 Schwering I, Bräuninger A, Distler V, Jesdinsky J, Diehl V, Hansmann ML, Rajewsky K, Küppers R: Profiling of Hodgkin's lymphoma cell line L1236 and germinal center B cells: identification of Hodgkin's lymphoma-specific genes. Mol Med 2003;9:85-95.
14 Wu X, Zeng H, Zhang X, Zhao Y, Sha H, Ge $\mathrm{X}$, Zhang M, Gao X, Xu Q: Phosphatase of regenerating liver- 3 promotes motility and metastasis of mouse melanoma cells. Am J Pathol 2004;164:2039-2054.

15 Bessette DC, Qiu D, Pallen CJ: PRL PTPs: mediators and markers of cancer progression. Cancer Metastasis Rev 2008;27:231-252.

16 Jemal A, Bray F, Center MM, Ferlay J, Ward E, Forman D: Global cancer statistics. CA Cancer J Clin 2011;61:69-90.

17 Jung YD, Nakano K, Liu W, Gallick GE, Ellis LM: Extracellular signal-regulated kinase activation is required for up-regulation of vascular endothelial growth factor by serum starvation in human colon carcinoma cells. Cancer Res 1999;59:4804-4807.

18 Mylona E, Nomikos A, Alexandrou P, Giannopoulou I, Keramopoulos A, Nakopoulou L: Lymphatic and blood vessel morphometry in invasive breast carcinomas: relation with proliferation and VEGF-C and -D proteins expression. Histol Histopathol 2007;22:825835.

19 Weidner N: Current pathologic methods for measuring intratumoral microvessel density within breast carcinoma and other solid tumors. Breast Cancer Res Treat 1995;36:169180.

20 Ferrara N: VEGF and the quest for tumour angiogenesis factors. Nat Rev Cancer 2002;2: 795-803

21 Astekar M, Joshi A, Ramesh G, Metgud R: Expression of vascular endothelial growth factor and microvessel density in oral tumorigenesis. J Oral Maxillofac Pathol 2012;16:22-26. 